\title{
A RELAÇÃO ENTRE ARTE E IMAGINÁRIO SEGUNDO JEAN-PAUL SARTRE
}

Rúbia Lúcia Oliveira ${ }^{1}$

\begin{abstract}
RESUMO
Por meio da análise da consciência e da formação do imaginário, Jean-Paul Sartre faz um percurso que demonstra como acontece a formação da obra de arte, isto é, do objeto passível de apreciação estética. Explica que existem diferentes motivações que desencadeiam a atuação da consciência imaginária assim como há diferença entre as obras de arte. Além disso, por meio do movimento fenomenológico, explica como o para-si percebe-se como um nada e, dessa forma, tem a compreensão da própria realidade.
\end{abstract}

PALAVRAS-CHAVE: Imaginário. Arte. Consciência.

\begin{abstract}
Through the analysis of consciousness and the formation of the imaginary, Jean-Paul Sartre takes a course that shows how the formation of the work of art, that is, of the object subject to aesthetic appreciation, takes place. It explains that there are different motivations that trigger the action of imaginary consciousness just as there is difference between works of art. In addition, through the phenomenological movement, it explains how the for-itself perceives itself as a nothingness and, in this way, has the understanding of reality itself.
\end{abstract}

KEY WORDS: Imaginary. Art. Consciousness.

A obra $O$ Imaginário de Sartre destaca como o objeto imaginário é formado, nesse sentido, a abordagem desse texto, possibilitará um entendimento acerca do modo como se constitui a relação entre arte e imaginário. A primeira advertência que o filósofo faz diz respeito à palavra consciência. Costumou-se dar a esta palavra um sentido de passividade $\mathrm{e}$ inércia, mas com Sartre ela passa a ter uma outra perspectiva. A imagem é para o filósofo um tipo de consciência como outra qualquer, por sua vez a consciência só existe como consciência desejante, imaginante, pensante, perceptiva. Esse aspecto permite considerar que em Sartre não existe consciência pura, portanto, essa palavra é usada para nomear diferentes estruturas psíquicas como: consciência de imagem, consciência perceptiva, emotiva entre outras.

\footnotetext{
${ }^{1}$ Doutora em Letras pela Universidade Federal do Tocantins. Professora Adjunta da Universidade Federal do Vales do Jequitinhonha e Mucuri, Campus JK.

Perspectivas - Revista do Programa de Pós-Graduação em Filosofia da UFT - n. 1 - 2019
} 
A partir de uma consciência sem objeto, e apoiando-se no conceito fenomenológico de intencionalidade, segundo o qual "toda consciência é consciência de alguma coisa", Sartre redefine a imaginação e a imagem. A palavra imagem designa a relação da consciência com o objeto, pois a imagem é uma certa maneira do objeto aparecer à consciência, um certo modo da consciência acercar-se do objeto, sendo que esta se caracteriza por uma determinada espontaneidade, isto é, na medida em que o homem se faz o tempo todo, não tendo uma essência anterior; primeiro tem-se que ter consciência de algo, e esta tem seu surgimento ex nihilo. "A palavra imagem não poderia, pois, designar nada mais que a relação da consciência ao objeto; dito de outra forma, é um certo modo que o objeto tem de aparecer à consciência ou, se preferirmos, um certo modo que a consciência tem de se dar um objeto" (SARTRE, 1996, p. 19).

A percepção também é uma consciência, uma maneira de lidar com o objeto. Ao perceber alguma coisa há uma interação com o real, o ato de perceber envolve um saber lento, na medida em que ao olhar uma cadeira, por exemplo, pode-se apreender cada uma de suas partes sem pressa. O objeto não é dado por inteiro, de uma só vez, é possível "transitar" por suas diversas aparências com o intuito de perceber todas as suas qualidades. $\mathrm{Na}$ percepção, um saber se forma lentamente, isto é, não acontece uma apreensão do objeto de forma instantânea. Com certeza é necessária uma observação no ato de perceber, de maneira que o objeto percebido mantenha uma relação com outras coisas ao seu redor, daí a infinidade de detalhes possíveis ao provocar a consciência perceptiva. O objeto da percepção excede constantemente sua consciência. Na percepção, observo o objeto. Isto quer dizer que posso multiplicar os pontos de vista sobre ele, posso girá-lo, vê-lo de um lado, de outro. O objeto, por sua vez, me aparece apenas por perfis, por facetas (MOUTINHO, 1995, p. 36). A citação de Moutinho sublinha alguns aspectos importantes sobre a percepção. No entanto, para Sartre, ela tem um sentido mais amplo, à medida que não se é totalmente passivo na percepção, pois ela envolve a atividade constituinte do sujeito. Minha percepção não se reduz aos perfis que capto porque ultrapasso isso que me é dado e vou em direção ao objeto total, isto é, por meio de uma antecipação percebo o objeto em um conjunto. O que não quer dizer perceber todo o conjunto da mesma forma, pois, não percebo o fundo de meu campo visual da mesma forma que percebo o objeto adiante.

Não percebo o objeto que destaco (a 'figura') tal como percebo o resto de meu campo perceptivo (o 'fundo'), mas eu sempre percebo um objeto em um campo, segundo o modelo figura/fundo, que tanto serviu à psicologia da Gestalt. [...] De tudo isso, resulta, enfim, um poder do sujeito pelo qual é legítimo dizer que ele

Perspectivas - Revista do Programa de Pós-Graduação em Filosofia da UFT - n. 1 - 2019 
organiza seu campo e, portanto, que ele nada tem de passivo, como supõe o modelo estímulo-resposta" (MOUTINHO, 2006, p. 205).

É importante ressaltar que na percepção, está-se lidando com o real, não com o imaginário, por isso é preciso ter contato com o objeto para percebê-lo. Em nenhum momento o ato de perceber remete ao processo de ser criador. Por mais que se possa apreender o objeto, ao observar suas várias faces, não se cria nada. Para se começar a criar é necessária a consciência imaginativa. Isso explica o fato de a percepção poder enganar enquanto a imagem não. "[...] quer eu perceba, quer eu imagine essa cadeira, o objeto de minha percepção e o de minha imagem são idênticos [...] Simplesmente a consciência se relaciona com essa mesma cadeira de dois modos diferentes" (SARTRE, 1996, p. 19). No primeiro caso ela constitui o objeto, no segundo cria, ou seja, produz, o objeto. O objeto percebido existe tanto para mim como para os outros que o veem; a imaginação é, primeiramente, dada somente a mim.

No caso da imagem, tem-se, pois, o objeto na consciência de uma só vez, sendo seu saber imediato, assim, só se tem a imagem do que se conhece do objeto. Por exemplo, na formação imaginária da cadeira do meu quarto, não posso ter dessa imagem algo que já não saiba dela de antemão, já que, na imagem, o objeto é apreendido sem mediações. Por isso, ao dizer que tenho a imagem de uma cadeira, estou emitindo um julgamento necessariamente verdadeiro, que não dá margens a erros ou dúvidas, ao contrário do que acontece com a percepção, pois ao dizer que percebo uma cadeira, posso estar enganada e perceber logo em seguida que se tratava de um outro objeto diferente do primeiro. Como afirma Sartre, “[...] no próprio ato que me dá o objeto como imagem já se encontra incluído o conhecimento do que ele é" (SARTRE, 1996, p. 23).

Segundo o filósofo, muitas teorias falharam ao tentarem explicar a natureza da imagem. O erro de muitos psicólogos e estudiosos da área, até hoje, foi pensarem que a imagem é uma forma menor de percepção, quando, na verdade, são duas estruturas completamente diferentes e excludentes. "Ao analisar a filosofia de Sartre, é deveras crucial reconhecer, desde o início, que ele acredita serem reais os objetos de que temos percepção consciente: serem fragmentos do mundo real" (DANTO, 1975, p. 42). A imagem não é uma coisa em miniatura porque senão ela seria algo inerte como os objetos do mundo. Poder-seia, nesse caso, lidar com a imagem como se lida com qualquer objeto concreto, como por exemplo, contar as colunas do Panteão imaginando-o. Curiosamente, nota-se que a imagem não é coisa, ela não é um conjunto de qualidades sensíveis reais. Ela é algo da ordem da Perspectivas - Revista do Programa de Pós-Graduação em Filosofia da UFT - n. 1 - 2019 
criação, vem à consciência de uma só vez. Ao criar a imagem do Panteão, não se tem dessa imagem nada além do que realmente se conhece desse objeto. Nesse sentido, não se é capaz de aprender nada nesse processo de criação da imagem, porque o fato de tê-la criado, já é suposto que se saiba tudo a seu respeito, a fim de formá-la no espírito.

Em A Imaginação, Sartre mostra que na concepção clássica o que diferencia a percepção e a imagem é a intensidade, nomeia tal concepção de a "metafísica ingênua da imagem". Nesse livro, analisa as teorias de Descartes, Hume, Leibniz e Bergson a respeito da imagem, pontuando que todas essas teorias, e, principalmente, as dos psicólogos, identificam a imagem com a percepção. Além disso, ressalta que após a identificação, esses teóricos distinguem ambas (imaginação e percepção) no âmbito dos conceitos de falso e verdadeiro, ficando a última como se fosse a representação verdadeira, na medida em que corresponderia ao real, e a primeira como a imagem falsa, por não corresponder ao objeto tal como ele seria "realmente". O erro, neste caso, consiste em pensar que a imagem também é real. A esse respeito Sartre afirma que:

Nessas três soluções a imagem guarda uma estrutura idêntica. Permanece uma
coisa. Apenas se modificam suas relações com o pensamento, de acordo com $o$
ponto de vista que se assumiu a respeito das relações com o pensamento, do
homem com o mundo, do universal com o corpo. Seguindo o desenvolvimento
contínuo da teoria da imagem através do século XIX, talvez verifiquemos que
essas três soluções são as únicas possíveis, desde que se aceite o postulado de que
a imagem nada mais é do que uma coisa e que todas elas são igualmente
possíveis e igualmente defeituosas. Ela continua uma coisa. Apenas suas relações
com o pensamento se modificam [...] E essas três soluções são as únicas possíveis
desde que aceitemos o postulado de que a imagem é apenas uma coisa e que elas
são todas igualmente possíveis e igualmente defeituosas (SARTRE, 2987, p. 44).

Portanto, como foi explicado na citação acima, para o autor, a imagem não pode ser consciência e conteúdo sensível ao mesmo tempo, como propôs a tradição clássica. O erro dessa concepção está em assinalar que a imagem em alguns momentos é vista como coisa, e em outros como uma cópia menor da percepção.

Ao tomar conhecimento das teorias de Husserl por volta de 1933, Sartre se entusiasmou bastante, já que a maneira como o pai da fenomenologia introduz o conceito de intencionalidade muda a visão que se tinha, até então, da imagem e da consciência.

\footnotetext{
A fenomenologia parecia prometer uma fuga de muitas coisas, não apenas da generalidade, mas também daquela espécie de preocupação com a subjetividade e a vida interior com as quais surrealistas e freudianos estavam exatamente ao mesmo tempo, programaticamente comprometidos (DANTO, 1975, p. 21).
}

Perspectivas - Revista do Programa de Pós-Graduação em Filosofia da UFT - n. 1 - 2019 
Sabe-se que a proposta da fenomenologia é entender o homem no mundo, em sua situação concreta, o que significa tratar a existência humana de forma bem inovadora pois, como afirmou Arthur Danto, a fenomenologia surgiu como uma alternativa diferente para a compreensão dos dramas existenciais do homem.

Apesar de Husserl não se dedicar a falar da imagem, ela passa a ser, a partir dele, uma consciência como outra qualquer, que se distingue completamente do seu próprio objeto, sendo assim, a consciência tem o mundo fora dela. Embora Sartre não concordasse com Husserl quanto à diferença entre imagem e percepção, para ele a noção de intencionalidade em Husserl foi fundamental, pois, a consciência é diferente daquilo que ela intenciona. "A intenção está no centro da consciência: é ela que visa o objeto, isto é, que o constitui pelo o que ele é” (SARTRE, 1987, p. 24). Ainda em O Imaginário o filósofo mostra que a imagem é definida por sua intenção, ela implica um saber. Desse modo a intenção se define pelo saber, pois a representação como imagem dá-se de algum modo pelo que se sabe, e da mesma forma, o saber, nesse caso, não é simplesmente um saber, é ato, é o que quero representar para mim intencionalmente. "O saber, que está indissoluvelmente ligado à intenção, especifica que o objeto é este ou aquele, acrescenta sinteticamente determinações" (SARTRE, 1987, p. 24).

Segundo Sartre, a imagem pode ser formada de várias formas, mas a negação do real é necessária para que ela aconteça. Nessa medida, a imagem sempre envolve um certo nada por mais realista que ela possa parecer, pois sempre visa seu objeto como não sendo. Ao contrário da relativa passividade da consciência perceptiva, a consciência imaginante se dá a si mesma como imaginante na medida em que produz e conserva seu objeto como imagem. A consciência imaginante visa os objetos por ela constituídos, é espontânea e criadora, mas a imagem possui um número finito de determinações que são exatamente aquelas de que temos consciência. Quando se quer formar a imagem de uma amiga que foi vista há três semanas e no momento está ausente, precisa-se negar a realidade da amiga em "carne e osso" que se encontra na sala de aula, para assim formar a sua imagem. Mas a imagem não corresponderá a da amiga deste momento, e sim uma imagem "universal", ou seja, uma imagem unificante de todas as formas já vistas daquela amiga. Portanto, a imagem precisa do real para negá-lo. E ao ter essa imagem, não estou tendo consciência da imagem de minha amiga, mas estou visando o objeto diretamente. 
Imagem não é portanto uma picture, uma tela na mente, é antes uma forma de consciência, uma forma da consciência do objeto, que sempre está fora, no mundo, no espaço, entre as coisas. [...] Sartre preserva o termo imagem, segundo ele próprio declara, apenas por seu uso universal. Mas deve-se entender por esse termo uma relação, não uma Picture" (MOUTINHO, 1995, p. 38).

Assim, ao contrário das teorias precedentes sobre o assunto, a imagem é uma forma de consciência intencional como as outras, forma esta diferente do objeto aparecer à consciência. Contudo é importante frisar que o objeto da consciência imaginante é diferente da consciência imaginante em si mesma, que tem regras próprias e durabilidade, por isso para que ele venha habitar essa consciência é preciso uma intenção que o vise e revele. “[...] uma consciência que seja simultaneamente consciência de si mesma seria uma inconsciência [...] (DANTO, 1975, p. 46). A imagem é na verdade um intuitivo-ausente, daí, porque não se pode perceber e ter uma imagem ao mesmo tempo. Quando se está na atitude perceptiva, necessariamente, se está fora da consciência imaginante, uma vez que o ato de imaginar envolve um ato de crença ou um ato posicional, que pode tomar a forma do objeto como inexistente, como ausente, como existente em outra parte ou ainda não colocar seu objeto como existente. Esses atos posicionais são constitutivos da consciência de imagem, ou seja, pensar alguém de forma conceitual é ainda pensar num conjunto de relações.

Para o autor dizer que pode haver imagem sem vontade não implica que possa haver imagem sem intenção, pois o que define o mundo imaginário tanto quanto o universo real é uma atitude da consciência. Pode-se usar de vários meios para chegarmos a ter uma imagem mental de um objeto, e mais uma vez o que fará a diferença é a intenção, pois os objetos imaginados servem como representantes dos objetos ausentes. É importante salientar que para Sartre não basta a intenção a fim de que se diferencie percepção e imaginação como em Husserl. É preciso que as matérias se diferenciem, pois a imagem é "nada", não tem a "carne" que forma o objeto. É o caso de uma fotografia, de uma caricatura ou de uma imitação.

Essa posição de ausência ou de inexistência só pode ser encontrada no plano da quase-observação. De uma parte, a percepção coloca a existência de seu objeto; de outra parte, os conceitos, o saber coloca a existência de naturezas (essências universais) constituídas por relações e são indiferentes à existência "em carne e osso" dos objetos. [...] É somente no terreno da intuição sensível que as palavras "ausente", "longe de mim" podem ter um sentido que se dá como podendo não ter lugar" (SARTRE, 1987, p. 26).

Certos julgamentos da percepção também envolvem um ato posicional neutralizado. Isso acontece, por exemplo, quando se vê uma pessoa vindo em nossa direção e se diz que é 
possível que seja determinada pessoa. Essa dúvida, ou melhor, a possibilidade que seja uma determinada pessoa, implica uma posição de existência em relação ao objeto. "O objeto intencional da consciência imaginante tem isto de particular: que ele não está aí e é posto como tal, ou que ele não existe e que é colocado como inexistente, ou ainda, que não é colocado de modo algum" (SARTRE, 1987, p. 27). Como se pode perceber a partir do próprio Sartre, a imagem tem vários modos de existir, e por isso mesmo Sartre alertou para o fato de usarmos a mesma palavra "imagem" para objetos que fazem parte do mundo exterior, como os retratos, reflexos no espelho e imitações. A questão, porém, é que a consciência imaginante se dá a si mesma como imaginante, como uma espontaneidade que produz e conserva o objeto como imagem. Nesse caso, a consciência aparece para si mesma como criadora, ou seja, a imagem sempre está relacionada a um nada. Ao olhar um quadro, por exemplo, e reconhecer nele um amigo, o quadro deixa de ser objeto e passa a ser a matéria da imagem. Passa-se a ter a imagem de um amigo a partir de um analogon (que no caso é o quadro). Neste momento, se vê o amigo e não o quadro, e não importa se esse amigo já morreu ou não, é como se ele estivesse presente na medida em que o tenho em imagem. Por isso, segundo Sartre, a relação que a consciência imaginante mantém nessas situações é mágica. O mesmo acontece no caso das palavras, porque elas na verdade despertam uma significação que vai em direção ao objeto cuja presença intuitiva é dispensável.

O imaginário é uma maneira de se chegar ao "Nada radical", pois o homem é uma espécie de instrumento que permite o Nada vir ao mundo na medida em que é fundamentação da negação. Ao apreender-se o Nada, está-se na verdade apreendendo o próprio Ser. Sendo um projeto reconstituinte, a nadificação realizada pelo imaginário exige o ser. Dessa forma, a imaginação está o tempo todo em tensão, pois ela, ao mesmo tempo, nega o real e precisa dele para seu objetivo: presentificar o objeto ausente. Nessa perspectiva, pode-se afirmar que na medida em que se insere no mundo a imaginação é capaz de negá-lo. Ela não consegue trazer o objeto para o mundo real: ele sempre estará no irreal. A contradição está em querer levar a esse absoluto qualidades próprias do sensível.

Por meio do imaginário nega-se o mundo real e para constituí-lo como fundo da imagem é preciso que a consciência coloque uma tese de irrealidade e seja totalmente livre. Essa situação possibilita a compreensão de que essa busca pelo Em-si-Para-si que caracteriza o homem é essencial, necessária e também irrealizável. Pois o homem ao imaginar, ao fazer o movimento do ser ao nada, consegue compreender os desejos e frustrações que lhe são 
próprios. A expressão da liberdade humana enquanto consciência nadificadora aponta para o homem como um ser complexo e ambíguo e, também, para a imagem, pois, o recurso a esta mostra em cada ato a questão que o homem é para si mesmo, ou seja, desejo de alienarse, de realizar o em-si-para-si, mas, também, a impossibilidade de realizar autenticamente esse desejo. $\mathrm{O}$ desejo revela a complexidade e ambiguidade humanas.

Quanto a essa posição em que o homem se vê e é visto como dividido, redimensionado a partir do desejo, é importante considerar a psicanálise. Freud também trata dessa questão e para ele o desejo é inconsciente e tende a realizar-se restabelecendo, de acordo com as leis do processo primário, os sinais ligados às primeiras experiências de satisfação. Assim como no modelo do sonho, o desejo encontra-se nos sintomas e nas outras formações do inconsciente sob a forma de retorno do recalcado e como formação de compromisso com o "eu" e com o inconsciente. O desejo é na verdade a vivência de uma satisfação, ele está relacionado aos registros de "traços mnésicos" e realiza-se na reprodução alucinatória das percepções tornadas sinais dessa satisfação. Dentro desta pauta é fundamental retomar a reflexão de Sartre sobre o imaginário, com vistas a estabelecer outras questões expostas por ele. Não daremos ênfase à questão psicanalítica aqui pelo fato de não ser esse nosso objetivo.

\footnotetext{
a imaginação não é um poder empírico e que se acrescenta de fora à consciência, mas a consciência total enquanto realiza a sua liberdade; toda situação concreta e real da consciência no mundo está prenhe de imaginário, à medida em que sempre se apresenta como um ultrapassamento do real [...]. As diferentes motivações é que decidem, a cada instante, se a consciência será apenas realizadora ou se imaginará. [...] Conceber uma consciência que não imaginasse, seria concebê-la totalmente engolfada no existente [...]. Em resumo, a motivação concreta da consciência imaginante pressupõe, ela própria, a estrutura imaginante da consciência; a consciência realizadora sempre envolve um ultrapassamento a uma consciência imaginante particular; é como que o inverso da situação e aquilo pelo qual a situação se define. (SARTRE, 2002, p. 123).
}

Portanto, como é explicado na Crítica da Razão Dialética, existem diferentes motivações que desencadearão a atuação da consciência imaginária. Mas, certo é que essa consciência sempre, por meio de seu próprio movimento, permitirá que o para-si perceba-se como um Nada. A contradição da necessidade e da impossibilidade simultâneas de realizar o projeto em-si-para-si fica muito clara no ato de imaginar, pois, justamente por ser negação, o imaginário é recuo e imersão no real. Enfim, para que se consiga negar o mundo é preciso inserir-se ainda mais nele, para conseguir criar a imagem de uma amiga ao olhar sua caricatura, preciso antes estar no mundo, negar a realidade visível que constitui justamente Perspectivas - Revista do Programa de Pós-Graduação em Filosofia da UFT - n. 1 - 2019 
"a motivação concreta" da consciência imaginativa e, assim, criar a irrealidade, que é essa amiga ausente, a qual por meio da imagem se presentifica de alguma forma. O paradoxo está no fato de o homem ter consciência de que é um ser que desvenda e não pode, ao mesmo tempo, produzir; em outras palavras, simultaneamente, é o para-si que dá significado ao emsi, mas, se sabe que o em-si existe independentemente do para-si. Daí o sentimento de impotência e insignificância sentido pelo homem ao contemplar uma paisagem, ele está diante da constatação de ao mesmo tempo ser desvendante e inessencial em relação ao objeto. Contudo, existe nele o desejo de tornar-se essencial em relação ao mundo, ao deixar de perceber um objeto, ele perde seu significado, mas não perde a existência, faz-se a criação artística. O desejo do homem de tornar-se em-si-para-si é, portanto, impossível, ou seja, a "paixão inútil" é uma busca incessante que define o homem.

Em suma, o ser é e não pode senão ser. Mas a possibilidade própria do ser - a que se revela no ato nadificador - é ser fundamento de si como consciência pelo ato sacrifical que o nadifica; o Para-si é o Em-si que se perde como Em-si para fundamentar-se como consciência (SARTRE, 1999, p. 131).

Nesse sentido, na medida em que o homem é o para-si que se torna consciente por meio do em-si, o artista é aquele que quer esse impossível, quer alcançar o Em-si-Para-si através da criação, o que significa, para ele, uma forma de se sentir essencial em relação ao mundo. Porém, sendo o homem um nada, um para-si que deseja ser, trata-se de uma busca pela síntese impossível. Portanto, esse desejo de se tornar essencial é a escolha comum e mais profunda em todos os artistas, tanto em relação àqueles que lidam com arte significante quanto em relação aos que lidam com a arte não significante, pois o que se busca é a essencialidade em relação ao objeto. Aqui, não se pode mais lidar com a percepção, à medida que é através dela que se desvenda o mundo e se dá conta da inessencialidade. Assim, precisa-se de outra maneira para se relacionar com o objeto; é preciso criar e, consequentemente, imaginar para se almejar a essencialidade na instância do desejo.

Para a fenomenologia, consciência é consciência de alguma coisa, e sendo a imagem consciência intencional, ela é imagem de alguma coisa, sendo assim, a consciência é acima de tudo um nada que visa um ser, um objeto com o qual jamais poderá coincidir. A coisa é uma existência em si, enquanto a consciência é uma existência para si: a consciência é sempre consciência do que ela própria o é. A intencionalidade que caracteriza a consciência é justamente a necessidade de existir como consciência de outra coisa que não ela, pois ela é o nada, é um movimento de fuga, enfim, de transcendência.

Perspectivas - Revista do Programa de Pós-Graduação em Filosofia da UFT - n. 1 - 2019 
a consciência torna-se vazia, um puro movimento para fora de si para se relacionar com coisas que ela não é, pura transcendência que só mantém como "imanência" essa consciência não tética de si ou, como depois será chamado, o cogito préreflexivo (condição de toda reflexão) (JACOBELIS, 2003, p. 63).

Como explica Jacobelis, a consciência, o para-si, está sempre em direção ao em-si, e nesse movimento percebe-se como nada. Portanto, a imagem não passa de uma maneira que a consciência tem de transcender. Pelo fato de ser sempre clara, não há inconsciente na consciência, a consciência na verdade é sempre consciência de si mesma, mas, consciente não teticamente de si, enquanto é consciência tética de um objeto transcendente. Dessa forma a imagem tem consciência de imagem enquanto surge, ela é ato e não coisa. A consciência transcendente da árvore como imagem coloca a árvore; mas coloca-a como imagem, isto é, de uma certa maneira que não é a da consciência. Baseado nessa teoria, Sartre explica a relação da imagem com o pensamento, explicitando a diferença entre percepção e imagem, explica que ao vermos algum objeto sensível como um quadro podemos escolher vê-lo como imagem ou como percepção, o que não acontece com a imagem mental, que é uma certa maneira que o objeto tem de estar ausente no próprio seio de sua presença (SARTRE, 1987, p. 103).

Na primeira parte de O Imaginário, denominada "O certo", Sartre afirma que o ato de reflexão possui o conteúdo imediatamente certo que ele chama de essência da imagem. A essência da imagem consiste em ela ser um fenômeno de quase-observação, no fato da consciência imaginante colocar seu objeto como o nada e no fato dela ser pura espontaneidade. É fundamental para a compreensão desse fenômeno entender a relação que a percepção e a imagem mantêm com o objeto. Tanto uma como a outra são consciências, mesmo que não sejam consciências téticas do objeto, elas se relacionam com ele, mas não de maneira idêntica, uma vez que cada qual possui uma maneira de posicionar as coisas. Assim, um objeto pode ser dado através da percepção, da imaginação ou da concepção. Na percepção, ele nos é dado através da observação, ou seja, por perfis, havendo assim uma certa atividade de aprendizagem. Na concepção, ao contrário, não há aprendizado à medida que se pode pensar o objeto em sua totalidade de uma só vez, pensa-se um saber que é consciente de si, uma vez que o objeto é apreendido por inteiro. A concepção é um saber completo do objeto como representação conceitual dos seis lados de um cubo que não podemos perceber simultaneamente. 
Contudo, é importante ressaltar que na imaginação o objeto também pode se dar por perfis, a diferença é que não há aprendizado não se acumulando visões, como acontece na percepção em relação a um determinado objeto. A imagem encontra-se, portanto, entre a percepção e a concepção, nela há uma pobreza essencial na medida em que apenas se encontra o que ali foi colocado, não existe uma relação entre os elementos da imagem com o resto do mundo como há na percepção, somente algumas poucas relações que se dão como um todo. Daí porque Sartre caracteriza a imaginação por quase-observação. Ela não é, como na percepção, uma observação, nem um saber consciente de si como na concepção. A imagem encontra-se neste meio, é uma observação que nada aprende. O que assemelha o objeto da imagem à percepção é o fato de ele ser contemporâneo da consciência, e em relação à concepção a semelhança está no fato de que tudo que contribuiu para a constituição da consciência encontra seu correlativo no objeto também.

Já afirmamos anteriormente que o modo como a consciência imaginante coloca seu objeto é diferente de como a percepção o faz. Esta coloca seus objetos como existentes, mesmo que apenas conceitualmente. Já nas quatro formas da imagem colocar seu objeto pode-se supor uma negação explícita ou implícita da existência natural e presente do objeto. A imaginação, ao contrário da percepção e da concepção, coloca o objeto como um nada de ser, ela envolve o nada. O extremo da liberdade e espontaneidade encontram-se na imaginação na medida em que ela se põe como criadora através da negação do objeto percebido, por isso a imagem é temporal, espontânea e criadora, o que não quer dizer que a imaginação seja superior às demais consciências. É possível atribuir à imagem, apesar desse aspecto de liberdade, uma limitação pelas determinações das quais se tem consciência, diferentemente do que acontece na percepção, quando o objeto percebido sempre ultrapassa as determinações da consciência. "No mundo da percepção, nenhuma "coisa" pode aparecer sem que mantenha com as outras coisas uma infinidade de relações. [...] a cada instante, há sempre infinitamente mais do que o que podemos ver; para esgotar a riqueza de minha percepção atual, seria necessário um tempo infinito" (SARTRE, 1987, p. 22). Isso significa que ao observar-se, ou melhor, ao se ter uma consciência perceptiva em relação a um objeto, pode-se sempre se ter um detalhe a mais, isto é, há uma infinidade de aspectos a serem apreendidos. 
Em O Imaginário, Sartre mostra como se dá esse afastamento do real por meio da negação, explica que na impossibilidade da percepção do objeto podemos recorrer a três modos de se lembrar dele: pela representação mental, quando imagino o objeto sem ter detalhes; a foto, que ajuda nos detalhes externos; e a caricatura, ajudando na lembrança das expressões. Nesses três casos, a intenção usa um determinado objeto como, por exemplo, Pierre. Essas três matérias servem como analogon, como representante analógico do objeto ausente. A diferença da teoria sartriana da imagem em relação às demais está em que para o autor a imagem é toda forma de visar um objeto ausente que faz uso de um analogon. "A consciência imaginante que tenho de Pierre não é a consciência da imagem de Pierre: Pierre é diretamente atingido, minha atenção não é dirigida para uma imagem, mas para um objeto" (SARTRE, 1987, p. 19). A imagem torna presente um objeto ausente. A consciência é espontânea na medida em que não é teticamente consciência de si mesma como imaginação e coloca seu objeto, como acontece ao usar uma fotografia, como analogon. Nesses casos, a semelhança entre o analogon e a imagem mental é mais forte. Em outros casos, como nos desenhos esquemáticos, essa relação é mais fraca, sendo necessários outros fatores como a afetividade, o saber e o movimento para equilibrar a relação. Mas tudo isso serve para evocar a imagem desejada. Sartre relata um caso de imitação e afirma que no momento em que a pessoa percebe o imitado a estrutura da consciência muda, passando a ser imaginária. Nesse caso é preciso "realizar meu saber na matéria intuitiva que me é fornecida" (SARTRE, 1987, p. 59). Isso quer dizer que se precisa de complementar o esquema analógico com afetividade, saber ou movimento. No caso dos desenhos esquemáticos, tem-se a necessidade do movimento do globo ocular para conseguir formar uma imagem e, assim, perceber que ela surge a partir da compreensão da totalidade, quando o saber significante se torna saber imaginante. No caso das imagens hipnagógicas, a semelhança entre o analogon e o objeto ausente é tão pequena que a consciência fica fascinada, ou seja, aprisionada pela imagem e se torna presa de si mesma. Em todos os casos relatados por Sartre, a intenção é sempre animar determinada matéria para fazer dela a representação de um objeto ausente ou inexistente, mesmo com a matéria e o saber variando nos diferentes casos.

$\mathrm{Na}$ quarta parte de $O$ Imaginário, tratando do objeto irreal, o filósofo afirma que o ato de imaginar é um ato mágico, um encantamento e o objeto como imagem é um irreal. Diante disso pode-se entender o imaginário como alienação. Parece, realmente, que o imaginário é uma forma de fuga da condição de ser no mundo. Nesse sentido, Sartre afirma 
que imaginar é um ato mágico na medida em que faz surgir um objeto que desejamos, o qual como imagem é um irreal. "[...] para agir sobre estes objetos irreais, é preciso que eu me desdobre, que me torne irreal" (SARTRE, 1987, p. 166). Portanto, todo ato da imaginação está lidando com a irrealidade. Isso é o mesmo que acontece na criação artística.

A composição artística recorre ao imaginário, e assim se consegue fugir da contingência e se vai ao encontro da liberdade do ser-no-mundo, por essa via nos tornamos necessários. Mas o homem só pode agir de modo imaginário diante desse mundo irreal criado por ele. Nesse momento pretende-se uma alienação, no entanto, é uma postura de má-fé, uma maneira de fugir da contingência para ficar no plano da necessidade, mesmo que para isso tenha que se viver num mundo irreal. Ficar totalmente no plano da necessidade como o em-si é, como vimos, impossível. Segundo $\operatorname{Sartre}^{2}$ o homem nega a si mesmo e explica esse fato por meio da noção de má-fé. O filósofo oferece alguns exemplos de conduta de má-fé. Um dos clássicos exemplos exposto por Sartre é o da mulher que não quer perceber as intenções do homem num primeiro encontro e se atém apenas às atitudes respeitosas do companheiro. A mulher nega seus desejos e encara o homem como um em-si para fugir das responsabilidades de seus atos. A conduta de má fé acontece em todos os campos de atuação da vida humana. "O protótipo das fórmulas de má-fé será dado por certas frases célebres, concebidas justamente para produzir o maior efeito, no espírito da má-fé" (SARTRE, 1987, p. 102). A atitude de má-fé é uma maneira do para-si negar a si mesmo e dessa forma ele esconde-se através vários subterfúgios.

Em A Náusea, romance de 1938, obra que o consagrou como escritor e filósofo, Sartre mostra o caso do personagem Roquetin, cuja forma de ver a arte está em alcançar a necessidade. É bom lembrar que as obras literárias de Sartre estão impregnadas de questões filosóficas. Nelas, pode-se pinçar toda a sua teoria filosófica e principalmente nessa obra estão evidentes os temas que mais o interessaram: temporalidade, angústia e liberdade.

É assim que Roquetin gostaria que fosse a sua vida: duração melódica, qualitativamente necessária, previsível e exata. Em cada momento dessa duração, pode-se esperar pelo que vai acontecer: a música não nos decepciona. Todos os instantes são necessariamente preenchidos; tempo e acontecimento regidos pela mesma necessidade (LEOPOLDO E SILVA, 2004, p. 91).

${ }^{2}$ Cf. Sartre (1999, p. 101). Não nos ateremos à explica de forma mais detalhada esse exemplo de conduta de má fé.

Perspectivas - Revista do Programa de Pós-Graduação em Filosofia da UFT - n. 1 - 2019 
Somente quando escuta uma música o personagem Roquetin consegue deixar de sentir a náusea, sentimento que se dá diante da constatação da pura contingência inerente à vida. Ele pretende através da criação de uma obra de arte sair dessa contingência. Então, de início parece que, no caso de Roquetin, o imaginário e a alienação relacionam-se. Na verdade, esse personagem sartriano é como os demais homens que buscam o em-si-para-si, mas não se pode afirmar que ele consegue alcançar seu objetivo, pelo menos não satisfatoriamente, ou melhor, plenamente. Enfim, nada garante que a escrita de um livro, ou qualquer outro tipo de recurso artístico proporcione a concretização do desejo de alienação. De maneira que o personagem Roquetin ao dizer: "Tinha perdido o primeiro jogo. Quis jogar o segundo e também perdi: perdi a partida. Concomitantemente aprendi que se perde sempre. Só os salafrários pensam que ganham" (SARTRE, 2005, p. 229), é possível desdobrar duas conclusões? Ou Roquetin não ganhou, ou seja, não alcançou seu objetivo de fugir da contingência, ou ele é um salafrário que apenas pensou que ganhou, pensando que através do livro tinha realizado seu desejo de ser em-si-para-si. Por isso, quando alguém pensa que está fugindo da contingência do real na verdade está agindo na má-fé, pois a realização plena da necessidade, da isenção da liberdade, é impossível. Em nenhum momento o homem consegue fugir da sua situação de pura liberdade e historicidade de forma total, porque mesmo ao se optar pela alienação está-se sendo livre. Pode-se preferir ficar no mundo irreal, mas isso ainda será uma escolha. E o mesmo podemos dizer do próprio Sartre. Ele também pensou poder realizar a "paixão inútil" que todo homem é, mas na verdade também não conseguiu. A pessoa pode negar o real e criar o irreal para fugir da contingência; trata-se de uma atitude que encerra uma crença sustentada pela liberdade. Mas a pessoa jamais consegue se alienar plenamente na necessidade.

\footnotetext{
A ilusão retrospectiva está reduzida a migalhas; martírio, salvação, imortalidade, tudo se deteriora, o edifício cai em ruínas, catei o Espírito Santo nas caves e o expulsei delas; o ateísmo é uma empresa cruel e de longo fôlego: creio tê-la levado até o fim. Vejo claro, estou desenganado, conheço minhas verdadeiras tarefas, mereço seguramente um prêmio de civismo; há quase dez anos sou um homem que desperta, curado de longa, amarga e mansa loucura, e que está perplexo, e que não consegue lembrar-se, sem rir, de seus antigos erros, o que não mais sabe o que fazer de sua vida" (SARTRE, 1970, p. 167).
}

Nessa citação de As Palavras, pode-se perceber como Sartre se sentia em relação à sua própria situação. Assim como seu personagem, ele não conseguiu fugir da contingência, ele não conseguiu alienar-se, por meio da escrita de suas obras, pelo contrário, sua confissão 
existencial revela o em-si-para-si que todo homem é. Sartre tem uma visão muito clara da real situação do homem: um ser livre, um para-si que ao contrário do em-si nunca tem um criador, não existe um Deus para lhe dar sentido.

É compreensível na frase proferida por Roquetin, que o imaginário possa ser uma forma de alienação, mas, de maneira paradoxal, pois exige uma maior inserção do homem no mundo, para que esse seja negado. É válido afirmar que a realização do em-si-para-si é apenas uma ilusão. A transcendência do imaginário, ou melhor, a possibilidade de negação do real só é possível devido à sua imanência ao mundo, pois o imaginário conhece bem o que nega, além disso, ao negar o real, conserva-o. "Curiosamente, a transcendência do sujeito a si mesmo implica a imanência da história à existência, paradoxo provavelmente inscrito na inevitabilidade da liberdade" (LEOPOLDO E SILVA, 2004, p. 182). Nisso consiste a ambiguidade do imaginário: ao mesmo tempo em que foge do mundo só é capaz de imaginar estando em situação neste. Ao modificar o mundo, a consciência insere-se ainda mais nele, pois o irreal criado tem sempre o real como pano de fundo. Dessa forma, entendemos que a teoria de Sartre sobre o imaginário não supõe o afastamento total de qualquer relação com o real, apesar de que no imaginário tanto se tem espaço para a alienação quanto para a necessidade. Souza mostra essa necessidade de inserção no real ao afirmar que:

o imaginário, na filosofia de Sartre não deve ser visto primordialmente como alienação e abstração, mas sim como uma imersão ainda mais profunda na realidade, justamente por ser negação, um afastamento do mundo que exige um mergulho ainda mais profundo da situação (SOUZA, 2004, p. 138).

Em A Náusea e em As Palavras, percebemos que a negação feita pelo imaginário apesar de afastar-se do real não o descarta. Em O Imaginário também, como mostraremos, a negação é paradoxal, isto é, fuga e inserção no mundo ao mesmo tempo. Outro aspecto interessante abordado por Sartre diz respeito à imaginação como um 'ato mágico', sendo assim, ela consequentemente ilude e engana. Portanto, pode-se dizer que esse ato mágico se dá no momento em que se pretende trazer à tona a qualidade do irreal, ou seja, no movimento de negação do analogon, pois, negando-o se faz surgir o irreal, o mágico.

Em Esboço de uma Teoria das Emoções, o filósofo afirma que essa tentativa de fuga da situação precisa do mundo real para realizar-se. O recuo e a negação feitos pela consciência imaginante são uma maneira da consciência ser no mundo e também de 
compreender sua condição de situada e inserida nele. Enfim, o encantamento próprio da imaginação é o que permite compreender a situação do homem. Por isso, por não poder ignorar o real, ela não é necessariamente alienação e abstração. Quanto ao objeto da imagem, Sartre o define como irreal, por ser negação do analogon. Sartre explica que o imaginário pode parecer uma oportunidade de se negar a situação existencial de situado no mundo, mas,

a evasão para a qual nos convidam (os analoga) não é apenas a que nos faria fugir de nossa condição atual, de nossas preocupações, de nossos tédios; eles oferecem uma escapada a todo tipo de constrangimento de mundo, parecem apresentar-se como uma negação de estar no mundo como um antimundo (SARTRE, 1987, p. 179, grifo nosso).

Portanto, o imaginário parece mesmo oferecer uma perfeita oportunidade para se fugir da realidade, da contingência, mas essa realização é apenas uma ilusão que logo se apresenta como frustração. Na medida em que é irreal não impõe nenhuma ação. Isso mostra como a consciência da imagem é mais livre e espontânea que as demais. O objeto da imagem é uma maneira de nos fazer afastar de nossa real condição de seres situados no mundo, ele é como uma negação da nossa condição, é como um antimundo. Mas apesar de o imaginário negar o mundo, não há simultaneamente a negação da condição humana de ser-no-mundo, pois o real continua como fundo da imagem. A condição humana torna-se ainda mais evidente nesse movimento. Ainda sobre essa questão Souza faz a seguinte análise:

Toda nossa tentativa de definir o imaginário como ambigüidade - concepção essa que nos parece mais coerente em relação ao pensamento de Sartre - fracassaria diante dessa afirmação se não fosse um detalhe: não há, nessa frase, a afirmação da possibilidade de fuga do ser-no-mundo (já que o verbo utilizado por Sartre é sembler, parecer, dar a impressão de), e a negação dessa afirmação, ou melhor, dessa hipótese, é feita explicitamente em uma nota colocada por Sartre em referência a essa frase citada. Na nota o filósofo diz que "être dans le monde" é a tradução do ser-no-mundo de Heidegger e que na conclusão será visto que essa concepção de que a imagem é negação da realidade humana como situação é apenas uma aparência, já que ela deve, ao contrário, constituir-se sobre o fundo do mundo. Há a negação do mundo no imaginário, mas não ocorre, junto com ela, a negação da condição humana de ser-no-mundo. A imagem permite o afastamento do mundo, mas não seu esquecimento: o mundo real, negado, continua como fundo da imagem. A condição necessária e essencial para que a consciência possa imaginar é justamente que ela seja situada, a transcendência exige a imanência" (SOUZA, 2004, p. 146).

A imagem é, portanto, como afirma Sartre, a negação do mundo de uma forma particular, sendo possível esse ato somente através da relação que o mantém como fundo. $\mathrm{O}$ irreal é produzido fora do mundo sem que a consciência deixe de estar no mundo. Isso porque 
não tem como eu deixar de estar no mundo, para criar a imagem, mas, pelo contrário, é na medida em que estou no mundo, situado, que posso criar o irreal, pois a consciência imaginante se dá quando não posso usar minha consciência perceptiva. Portanto, o imaginário não é apenas abstração e alienação, mas, também, a possibilidade de um recuo em relação ao mundo, fazendo com que o homem compreenda sua condição de ser livre e contingente. Porém, isso não impede que o imaginário seja usado de má fé, ou seja, como forma de alienação por escritores e outras pessoas. Nessa perspectiva, a imagem é para Sartre em si mesma uma contradição, já que há nela um grande poder persuasivo de má fé ao mesmo tempo que possibilita a compreensão da condição do homem de ser-no-mundo. Afinal, a imagem exige um ato de crença e uma inserção no mundo para negá-lo, nega-se o real para se criar o irreal. Ora, a imagem não é apenas má-fé, nem, tampouco, apenas possibilidade de compreensão do homem no mundo; o imaginário é uma ambiguidade em si ao negar o real e o manter ao mesmo tempo. Enfim, a imagem possibilita a compreensão daquilo que o conceito não consegue. Por sua vez, a prosa também é ambiguidade, pois lida com o significante e o imaginário, simultaneamente, e, dessa forma, por ser como a imagem é de suma importância para a compreensão da realidade humana.

Portanto, vimos que para Sartre a consciência imaginante permite que através da negação do real se dê a formação do irreal, tendo sempre o mundo como pano de fundo. Nesse sentido, o imaginário, assim como a literatura, é ambíguo. Justamente essa ambiguidade que nos permite a compreensão da realidade humana a partir da obra literária.

\section{REFERÊNCIAS BIBLIOGRÁFICAS}

BORNHEIM, G. Sartre: metafísica e existencialismo. São Paulo: Perspectiva, 1971.

BRIOSI, S. "L'imaginaire et l'esthétique de Sartre" In : Revue d'esthétique, hors série, Sartre/Barthes, 1991.

. "Un manifeste du désengagement” In: Revue Obliques, n. 24/25, 1981.

BURDZINSKI, J.C. Má-fé e Autenticidade: um breve estudo acerca dos fundamentos ontológicos da má-fé na obra de Jean-Paul Sartre Ijuí: Ed. UNIJUİ, 1999.

COELHO, I. Sartre e a interrogação fenomenológica do imaginário, tese de doutorado defendida na Universidade de São Paulo, 1978. 
DANTO, A. As idéias de Sartre, São Paulo: Cultrix, 1975.

DENIS, B. Literatura engajada de Pascal a Sartre. Bauru: EDUSC, 2002.

JACOBELIS. Temporalidade e Liberdade ou da Compreensão da Realidade Humana em O Ser e o Nada. O drama da existência: estudos sobre o pensamento de Sartre. ALVES, I. S. (Org.) São Paulo: Humanitas, 2003.

LEOPOLDO E SILVA, F. Ética e literatura em Sartre: ensaios introdutórios. São Paulo: Unesp, 2004.

"Metafísica e história no romance de Sartre" In Revista Cult, maio 2000.

MERLEAU-PONTY, Maurice: Fenomenologia da Percepção. Tradução de Reginaldo di Piero. Rio de Janeiro, Freitas Bastos S.A, 1971.

MÉSZAROS, István: A obra de Sartre: busca da liberdade. São Paulo: ed. Ensaio, 1991. MOUTINHO, L. D. Sartre: psicologia e fenomenologia. Dissertação de mestrado defendida na Universidade de São Paulo, 1993. Sartre: existencialismo e liberdade. São Paulo: Moderna, 1995. . "Negação e finitude na fenomenologia de Sartre" In Revista Discurso, n. 33, 2003. . O belo em Kant e Sartre. Lumen, São Paulo, v. II, n. 4, p. 63-74, 1996. . Sartre: A liberdade sem desculpas. In: Seis filósofos na sala de aula. Vinícius de Figueiredo (Org.). São Paulo: Berlendis\&Vertecchia, 2006.

PASCAL. Pensamentos. São Paulo: difusão européia do livro, 1961.

PERDIGÃO, P. Existência e liberdade: uma introdução à filosofia de Sartre. Porto Alegre: L\&PM, 1995.

SARTRE. A imaginação. Coleção Os Pensadores São Paulo: Nova Cultural, 1987. Crítica da razão dialética. São Paulo: DP\&A, 2002. . L'imagination. Paris: Presses Universitaires de France, 1965. O imaginário. São Paulo: ed. Ática, 1996. L'imaginaire. Paris: Gallimard, 1940. Que é a literatura? São Paulo: ed. Ática, 1993. . Qu'est-ce que la littérature?. Paris: ed. Gallimard, 1948. O ser e o nada: ensaio de ontologia fenomenológica. Petrópolis: Vozes, 1999. . A transcendência do ego. Lisboa: edições Colibri, 1994.

Perspectivas - Revista do Programa de Pós-Graduação em Filosofia da UFT - n. 1 - 2019 
. A Náusea. Rio de Janeiro: Nova Fronteira, 2005.

O Sequestrado de Veneza Tradução de Eloisa Araújo São Paulo: Cosacnaif, 2005. . As palavras. São Paulo: Difusão, 1970.

SCHWARZER, A. Simone de Beauvoir hoje Rio de Janeiro: Rocco, 1986.

SOUZA, T. M. A literatura para Sartre: A compreensão da realidade humana Dissertação de mestrado defendida na Universidade de São Paulo, 2004. 